Tropical Journal of Pharmaceutical Research September 2018; 17 (9): 1701-1709

ISSN: $1596-5996$ (print); 1596-9827 (electronic)

(C) Pharmacotherapy Group, Faculty of Pharmacy, University of Benin, Benin City, 300001 Nigeria.

\title{
Formulation development and optimization of orally disintegrating tablets of montelukast sodium by Design- Expert
}

\author{
Shahnaz Usman ${ }^{1 *}$, Rubina Rafiq Ejaz ${ }^{1}$, Kashif Ali Safdar ${ }^{2}$ \\ ${ }^{1}$ Department of Pharmaceutics, RAK College of Pharmaceutical Sciences, RAK Medical and Health Sciences University, Ras AI \\ Khaimah, United Arab Emirates, ${ }^{2}$ Department of Pharmaceutics, Faculty of Pharmacy, University of Karachi, Karachi, Pakistan \\ *For correspondence: Email: shahnaz.usman@rakmhsu.ac.ae, shahnazgauhar@gmail.com; Tel: +971 558902559; Fax: +971 \\ 72269997
}

\begin{abstract}
Purpose: To prepare orally disintegrating tablets (ODT) of montelukast sodium using Design-Expert for improved patient compliance.

Methods: Central composite design was selected to delineate and optimize the formulations. Concentrations of crospovidone $\left(X_{1}\right)$ and sodium bicarbonate $\left(X_{2}\right)$ were selected as the variables, and responses were based on friability (Y1) and disintegration time (Y2). Varying amounts of super disintegrating agents and effervescent bases were used with microcrystalline cellulose to prepare montelukast sodium ODT.

Results: Carr's index of montelukast sodium was $4.76 \pm 0.075$, indicating the good compressibility of powder. Whereas the Carr's value for microcrystalline cellulose and mannitol were $30.14 \pm 0.021$ and $22.41 \pm 0.053$ respectively. The FTIR spectra indicated that there were no major shifting and loss of functional groups in drug and excipients blends. Formulations were evaluated, check point batch (CPB, F2) was selected using Design-Expert. The friability of CPB tablets was found to be $0.27 \pm 0.085$; hardness, $4.96 \pm 0.093 \mathrm{kp}$; wetting time, $28 \pm 0.17 \mathrm{~s}$; disintegration time (DT), $28.34 \pm 1.78 \mathrm{~s}$; and drug release, $85.5 \%$ within 5 min.

Conclusion: The ODT of montelukast sodium has successfully been formulated by direct compression and optimized within a short period, thus demonstrating the suitability and stability of the formulation.
\end{abstract}

Keywords: Direct compression, Montelukast sodium, Orally disintegrating tablets, Super-disintegrants, Design Expert, Crospovidone

\footnotetext{
This is an Open Access article that uses a funding model which does not charge readers or their institutions for access and distributed under the terms of the Creative Commons Attribution License (http://creativecommons.org/licenses/by/4.0) and the Budapest Open Access Initiative (http://www.budapestopenaccessinitiative.org/read), which permit unrestricted use, distribution, and reproduction in any medium, provided the original work is properly credited.
}

Tropical Journal of Pharmaceutical Research is indexed by Science Citation Index (SciSearch), Scopus, International Pharmaceutical Abstract, Chemical Abstracts, Embase, Index Copernicus, EBSCO, African Index Medicus, JournalSeek, Journal Citation Reports/Science Edition, Directory of Open Access Journals (DOAJ), African Journal Online, Bioline International, Open-J-Gate and Pharmacy Abstracts

\section{INTRODUCTION}

Many patients especially in pediatrics and geriatrics do not like to take conventional tablet dosage form, because it is difficult to swallow, dysphagia [1] which is one of the major factors affecting the compliance to drugs use. The oral disintegrating tablets (ODT) formulation could help to enhance patient compliance because of its ease of administration and no liquid is required to take it $[2,3]$. A study was conducted on patients who were diagnosed with allergic 
rhinitis to assess the degree of acceptance and preference for fast dissolving tablets (FDT). The study comprised of 7,686 patients, $88 \%$ of which agreed to switch their current antihistaminic drug to a new FDT anti-allergy drug [4].

Based on the recent data, in the UAE, one in every six persons suffer from asthma [5]. Montelukast sodium is used to prevent and manage asthma symptoms and provide the symptomatic relief in seasonal allergies. Montelukast is an orally active compound that works by blocking the effects of leukotrienes and causes dilatation of airways in the lungs. If an appropriate and convenient drug product is developed, a better control over fulminant allergic responses can be achieved.

To improve the quality of medicines, the pharmaceuticals companies are facing decisive issues to design an optimized pharmaceutical formulation in a short period of time without series of trials. Design Expert is a computerbased optimization technique working on response surface methodology (RSM) that helps to utilize experimental designs and operating conditions in better ways $[6,7]$.

The aim of this study was to develop an ODT of montelukast sodium by direct compression method.

\section{EXPERIMENTAL}

\section{Materials}

Montelukast sodium was provided by MSN Pharmachem Private Ltd. India. Whereas crospovidone, mannitol, aspartame, cherry flavor and magnesium stearate were provided by Julphar-Gulf Pharmaceutical Industries, Ras Al Khaimah, UAE. Other chemicals that were used during the study included microcrystalline cellulose (Avicel pH-101) from Fluka-Biochemika Germany and sodium bicarbonate from Labchem products.

\section{Development of powder blend for compression}

The preliminary batches were prepared using different diluents namely microcrystalline cellulose and mannitol along with disintegrants such as crospovidone and sodium bicarbonate in a separate formulation [8]. From this pilot study, it was found that ODT containing microcrystalline cellulose as diluent and combination of crospovidone and sodium bicarbonate as disintegrants showed good balance between tablet hardness and disintegration time. Thus the same were considered for further studies.

All the ingredients were accurately weighed as per the respective formulation (Table 1) and passed through mesh \# $40(400 \mu \mathrm{m})$ separately to reduce the size of clumps and large fragments further enhance mixing properties and pellet ability of powder. It also increases the bulk density to some extent. Initially montelukast sodium, microcrystalline cellulose, sodium bicarbonate and crospovidone were mixed together in a poly bag for $5-10 \mathrm{~min}$. Then cherry flavor and aspartame were mixed in, afterwards magnesium stearate was added up into powder composition. The mixing time was set based on the uniformity of the parameter of unitary dose.

\section{Pre-formulation studies}

The micromeritics properties for individual components of formulation and powder mixtures were determined before compression of the tablets.

Table 1: Design of prototype formulations of montelukast sodium ODT

\begin{tabular}{|c|c|c|c|c|c|c|c|c|c|c|}
\hline \multirow[t]{2}{*}{ Ingredient } & \multicolumn{10}{|c|}{ Formulation code (mg/tablet) } \\
\hline & F1 & F2 & F3 & F4 & F5 & F6 & F7 & F8 & F9 & F10 \\
\hline $\begin{array}{l}\text { Montelukast } \\
\text { sodium }\end{array}$ & 5.20 & 5.20 & 5.20 & 5.20 & 5.20 & 5.20 & 5.20 & 5.20 & 5.20 & 5.20 \\
\hline $\begin{array}{l}\text { Microcrystalline } \\
\text { cellulose }\end{array}$ & 98.56 & 102.80 & 103.80 & 102.80 & 107.04 & 102.80 & 98.56 & 105.80 & 107.04 & 108.8 \\
\hline $\begin{array}{l}\text { Sodium } \\
\text { bicarbonate }\end{array}$ & 16.0 & 16.00 & 19.00 & 13.00 & 16.00 & 19.00 & 20.24 & 13.00 & 11.76 & 13.00 \\
\hline Crospovidone & 24.24 & 20.00 & 16.00 & 23.00 & 15.76 & 17.00 & 20.00 & 20.00 & 20.0 & 17.0 \\
\hline Aspartame & 2.00 & 2.00 & 2.00 & 2.00 & 2.00 & 2.00 & 2.00 & 2.00 & 2.00 & 2.00 \\
\hline Cherry flavor & 2.00 & 2.00 & 2.00 & 2.00 & 2.00 & 2.00 & 2.00 & 2.00 & 2.00 & 2.00 \\
\hline $\begin{array}{l}\text { Magnesium } \\
\text { stearate }\end{array}$ & 2.00 & 2.00 & 2.00 & 2.00 & 2.00 & 2.00 & 2.00 & 2.00 & 2.00 & 2.00 \\
\hline Total weight & 150.0 & 150.0 & 150.0 & 150.0 & 150.0 & 150.0 & 150.0 & 150.0 & 150.0 & 150.0 \\
\hline
\end{tabular}




\section{Angle of repose}

According to the USP, angle of repose for all individual ingredients and blends of powder were calculated by using Eq 1 .

$\operatorname{Tan}(\alpha)=h / 0.5 b$

\section{Bulk density}

For this study, $50 \mathrm{~g}$ of powder mixture was accurately weighed in a $100 \mathrm{ml}$ graduated cylinder. This mixture was carefully leveled without compacting and was read as the unsettled apparent volume $\left(\mathrm{V}_{\mathrm{o}}\right)$ [9]. Bulk density $(\mathrm{g} / \mathrm{ml})$ was calculated using Eq 2.

$\rho_{b}=\mathrm{Ms} / \mathrm{Vt}$

\section{Tapped density}

According to USP, the powder present in the graduated cylinder was tapped up to 500 times and the final tapped volume $\left(V_{t}\right)$ was measured. Tapped density was calculated based on Eq 3 and expressed in $\mathrm{g} / \mathrm{ml}$

$\rho_{t}=M_{t} / N_{t}$

\section{Compressibility index}

The compressibility index of the powder mixture was calculated as in Eq 4, using their bulk and tapped volumes.

$\mathrm{C}=100\left[\left(\mathrm{~V}_{\mathrm{B}}-\mathrm{V}_{\mathrm{T}}\right) / \mathrm{V}_{\mathrm{B}}\right]$

\section{Hausner ratio}

Eq 5 was used for the calculation of Hausner ratio which is an indirect measure of powder flow.

$\mathrm{H}=\rho_{\mathrm{T}} / \rho_{\mathrm{B}}$

\section{Drug-excipient compatibility studies}

In the development of the dosage form, there can be a possibility of interaction between drug and excipients. FTIR spectroscopy (Agilent Technologies, Cary 630 FTIR) was performed for all batches and components separately. The compatibility studies were done for montelukast sodium with different excipients.

\section{Preparation of tablets by direct compression}

Initially, the formula for montelukast sodium tablets was developed in different stoichiometric ratios from sodium bicarbonate and crospovidone, whereas all the other ingredients were same as that of Table 1. All powder blends were compressed on $7.0 \mathrm{~mm}$ round plain concave shaped punches at the theoretical weight of $150 \pm 7.5 \mathrm{mg} \%$. Flat-faced tablets were prepared by using a Cadmac D3 tablet compression machine, containing seven dies, and seven pairs of plane punches of $7 \mathrm{~mm}$ diameter each. Tablets were scrutinized on the bases of disintegration time and friability tests for further optimization and validation of formulations.

\section{Formulation optimization of ODT}

Upon attaining satisfactory results of friability and disintegration, the prototype formulation with favorable ratio of crospovidone and sodium bicarbonate was selected. In order to optimize the formulation, the concentration of crospovidone $\left(X_{1}\right)$ in a formulation and concentration of sodium bicarbonate $\left(X_{2}\right)$ with regards to disintegration time $\left(Y_{1}\right)$ and \% Friability $\left(\mathrm{Y}_{2}\right)$ were selected as the variables.

The optimization process was carried out with Design- Expert. Response surface model with central composite design was selected for this experiment. Hence two factors, five level central composite designs with two central points and 10 runs were used to optimize the selected parameters (Table 2). About 1000 tablets from each formula were produced as mentioned above (Table 1).

Table 2: Independent variables and their levels

\begin{tabular}{lcccc}
\hline Level & \multicolumn{2}{c}{ Crospovidone $\left(\mathbf{X}_{\mathbf{1}}\right)$} & \multicolumn{2}{c}{ Sodium bicarbonate $\left(\mathbf{X}_{\mathbf{2}}\right)$} \\
\cline { 2 - 5 } & Coding & $\begin{array}{c}\text { Actual value } \\
(\mathbf{m g})\end{array}$ & Coding & $\begin{array}{c}\text { Actual value } \\
(\mathbf{m g})\end{array}$ \\
\hline Low & -1 & 17 & -1 & 13 \\
Medium & 0 & 20 & 0 & 16 \\
High & +1 & 23 & +1 & 19 \\
Axial (-) & $-\alpha$ & 15.757 & $-\alpha$ & 11.757 \\
Axial (+) & $+\alpha$ & 24.243 & $+\alpha$ & 20.243 \\
\hline
\end{tabular}




\section{Quality attributes of tablets}

All the tablets had adequate consistency of weight, size, hardness and overall appearance.

\section{Weight variation}

Twenty tablets from each batch were weighed individually using weight variation test (analytical balance: Mettler Toledo; PB-153S), the mean and range of tablets were calculated as per the USP requirements [10].

\section{Hardness and thickness}

The hardness and thickness of 10 tablets from each batch were measured to determine the mechanical strength in order to handle the shipment and transportation of medicines (hardness tester: Pharmatron Dr. Schleuniger; $8 \mathrm{M}$ and vernier caliper: Mitutoyo -Japan). Hardness of tablets is an important quality control parameter, vital for the adjustment of disintegration time and friability of tablets.

\section{Friability test}

The friability test (Veego, VFT-2D) was conducted for all 10 batches (F1- F10) at $25 \pm 1$ rpm for four minutes. After de-dusting, the weights of tablets were recorded at both intervals i.e. pre test and post test and the friability was calculated as per the formula in Eq 6 [11].

Friability $(\%)=[(\mathrm{W} 1-\mathrm{W} 2) / \mathrm{W} 1] 100 \ldots . .(6)$

\section{Wetting time}

Based on tablet size, recommended volume of dye solution $(0.1 \% \mathrm{w} / \mathrm{v})$ was added into $10 \mathrm{ml}$ petri dishes. The tablets were carefully placed on the surface of the dye solution and finally the total wetting time was measured $[12,13]$.

\section{Disintegration test}

The disintegration time for ODT must be within a minute. It was carried out according to USP standards by using disintegration apparatus (Veego-VTD-D) [14].

\section{Dissolution test}

The in vitro release of montelukast sodium from tablets was measured on six units of each formulation (F1-F10) by using $0.2 \%$ sodium lauryl sulphate (SLS) with USP dissolution apparatus II (Labindia-D5 8000) at $50 \mathrm{rpm}$. The samples (10 $\mathrm{ml}$ ) were withdrawn from dissolution vessels at 2 , 5, 10, 15 and $30 \mathrm{~min}$, and replaced with fresh medium. The samples were analyzed spectrophotometrically on $\lambda=285 \mathrm{~nm}$ (Shimadzu; UV-1700). The dissolution test is used as a surrogate for bioavailability studies.

\section{Drug content assay}

10 tablets were ground into fine powder and 150 $\mathrm{mg}$ was transferred into $25 \mathrm{ml}$ volumetric flask i.e. equivalent to $5 \mathrm{mg}$ of montelukast sodium. The final concentration $(10 \mu \mathrm{g} / \mathrm{ml})$ of standard and sample solutions was prepared in methanol: water (MeOH: $\mathrm{H}_{2} \mathrm{O}$; 1:1) diluent. Amount of drug per tablet were analyzed spectrophotometrically at $\lambda=254 \mathrm{~nm}$. The USP limit per tablet is 92.5 $107.5 \%$.

\section{Preparation of check point batch (CPB)}

The results of disintegration and friability tests of all the batches were entered in the software. The number of independent variables, $X_{1}$ and $X_{2}$ were calculated for the optimized batch with target of $0.45 \%$ friability and less than 30 seconds for disintegration to obtain desirability equal to one. CPB was then prepared and evaluated as described earlier to confirm the validity and effectiveness of formulation design.

\section{Stability studies}

The CPB was blistered using blistering machine in Alu/Alu packing and subjected to accelerated stability studies $[15,16]$ as per ICH guideline [17] at $40 \pm 2^{\circ} \mathrm{C}$ and $75 \pm 5 \%$ R.H for 6 months. Tablets were evaluated at the intervals of $0,1,3$ and 6 months [18-21].

\section{Statistical analysis}

Formulation design and optimization was carried out with the aid of Design Expert 9.0.1 (State Ease Inc). For dissolution, Microsoft Excel add-in "DD Solver" v1.0. was used whereas analysis of variance ANOVA was determined for disintegration of tablets, where a $p$ value of less than 0.05 was considered statistically significant.

\section{RESULTS}

In this study the analytical method used for the determination of montelukast sodium was adopted from USP-37 under assay, Indian Pharmacopeia under dissolution and then modified and validated. The calibration curve for montelukast sodium in a mixture of methanol: water and $0.2 \%$ SLS was linear in the concentration range of $1.0-10.0 \mu \mathrm{g} / \mathrm{mL}$ as shown in Table 3. 
Table 4 shows the result of pre-formulation studies for the drug and excipients as raw materials used separately. Bulk density (BD), tapped density (TD), compressibility index (Carr's index), Hauser ratio $(H)$ and angle of repose $(\boldsymbol{\theta})$ were estimated to determine the best excipients to be used in the formulation development of montelukast sodium ODT.

After the preliminary study of the excipients to be used, microcrystalline cellulose (MCC) was selected as filler, crospovidone as superdisintegrant and sodium bicarbonate as dispersing agent. The quantitative calculation of disintegrating and dispersing agent was obtained by Design Expert. The bulk density and tapped density for all ten batches varied from 0.495 to $0.598 \mathrm{~g} / \mathrm{mL}$ and 0.540 to $0.788 \mathrm{~g} / \mathrm{mL}$, respectively. Carr's index values ranged from 8.148 to $23.51 \%$, highlighted the capability of different ratios of crospovidone and sodium bicarbonate in the formulation and showed the impact on the flow of powder blends. Hausner ratio values obtained were in the range of 1.09 to 1.32 whereas the frictional forces in a loose powder, measured by the angle of repose, were in the range of 27.63 to $36.81^{\circ}$, showing excellent to passable flow property of different powder blends based on the USP [22] (Table 5).

FTIR spectrophotometry was carried out for identification and affinity of formulation composition. Figure 1 shows the FTIR spectra for pure drug and blended mixture of drug and excipients. Pure drug showed the bond vibrations at $3396 \mathrm{~cm}^{-1}$ (COOH stretching), $3057 \mathrm{~cm}^{-}$ ${ }^{1}$ (aromatic C-H stretching), $2925 \mathrm{~cm}^{-1}$ (aliphatic $\mathrm{C}-\mathrm{H}$ stretching), and $1710 \mathrm{~cm}^{-1}(\mathrm{C}-\mathrm{O}$ stretching). The amalgam of drug and excipients didn't show any major shifting or loss of functional peaks between them.

After analyzing the pre-formulation parameters of powder mixture, it was compressed into a round shaped tablets with a bisect line on one side. The pharmaceutical features of tablets i.e. weight, thickness, hardness, disintegration and drug dissolution were controlled during the production of batches (Table 6). All tablets passed the weight variation test and were found to be within the acceptable limit of \pm 7.5 according to the USP [23].

Table 3: Linearity of Montelukast sodium in two diluents

\begin{tabular}{lccc}
\hline Diluent & Concentration range & $\begin{array}{c}\text { Equation } \\
\mathrm{Y}=\mathrm{mx}+\mathrm{b}\end{array}$ & $\mathbf{r}^{2}$ \\
\hline Methanol : Water $\left(\mathrm{MeOH}: \mathrm{H}_{2} \mathrm{O} ; 1: 1\right)$ & $1.0-10.0 \mu \mathrm{g} / \mathrm{ml}$ & $\mathrm{Y}=0.0408 \mathrm{x}+0.0005$ & 0.9997 \\
$0.2 \% \mathrm{SLS}$ (Sodium lauryl sulphate) & $1.0-10.0 \mu \mathrm{g} / \mathrm{ml}$ & $\mathrm{Y}=0.0342 \mathrm{x}+0.0025$ & 0.9996 \\
\hline
\end{tabular}

Table 4: Results of pre-formulation studies of montelukast sodium and excipients

\begin{tabular}{lccccc}
\hline Ingredient & $\begin{array}{c}\text { Bulk density } \\
(\mathbf{g} / \mathbf{m L})\end{array}$ & $\begin{array}{c}\text { Tapped } \\
\text { density } \\
(\mathbf{g} / \mathbf{m L})\end{array}$ & $\begin{array}{c}\text { Carr's index } \\
(\%)\end{array}$ & $\begin{array}{c}\text { Hausner's } \\
\text { ratio* }\end{array}$ & $\begin{array}{c}\text { Angle of } \\
\text { repose }(\theta)\end{array}$ \\
\hline Montelukast sodium & $0.20 \pm 0.011$ & $0.21 \pm 0.093$ & $4.76 \pm 0.075$ & $1.05 \pm 0.004$ & - \\
Microcrystalline & $0.34 \pm 0.014$ & $0.49 \pm 0.031$ & $30.14 \pm 0.021$ & $1.44 \pm 0.006$ & $36 \pm 0.014$ \\
cellulose & & & & & \\
Mannitol & $0.430 \pm 0.031$ & $0.56 \pm 0.071$ & $22.41 \pm 0.053$ & $1.30 \pm 0.007$ & $33 \pm 0.011$ \\
Sodium bicarbonate & $0.87 \pm 0.010$ & $1.16 \pm 0.088$ & $24.96 \pm 0.079$ & $1.33 \pm 0.005$ & $28 \pm 0.016$ \\
Crospovidone & $0.37 \pm 0.038$ & $0.42 \pm 0.095$ & $11.78 \pm 0.09$ & $1.135 \pm 0.001$ & $29 \pm 0.018$ \\
\hline
\end{tabular}

Table 5: Flow properties of the powder blend (mean $\pm S D, n=3$ )

\begin{tabular}{|c|c|c|c|c|c|}
\hline \multirow{2}{*}{$\begin{array}{l}\text { Formulat } \\
\text { ion code }\end{array}$} & \multirow{2}{*}{$\begin{array}{c}\text { Bulk density } \\
(\mathrm{g} / \mathrm{ml})\end{array}$} & \multirow{2}{*}{$\begin{array}{c}\text { Tapped } \\
\text { density }(\mathrm{g} / \mathrm{ml})\end{array}$} & \multicolumn{3}{|c|}{ Flow properties* } \\
\hline & & & $\begin{array}{c}\text { Carr's index } \\
\text { (\%) }\end{array}$ & $\begin{array}{c}\text { Hausner } \\
\text { ratio }\end{array}$ & $\begin{array}{l}\text { Angle of } \\
\text { repose * }(\theta)\end{array}$ \\
\hline F1 & $0.555 \pm 0.074$ & $0.665 \pm 0.070$ & $16.54 \pm 0.013$ & $1.20 \pm 0.003$ & $32.3 \pm 1.16$ \\
\hline $\mathrm{F} 2$ & $0.496 \pm 0.015$ & $0.540 \pm 0.019$ & $8.148 \pm 0.023$ & $1.09 \pm 0.005$ & $27.63 \pm 0.040$ \\
\hline F3 & $0.595 \pm 0.101$ & $0.788 \pm 0.101$ & $23.51 \pm 0.017$ & $1.32 \pm 0.001$ & $36.81 \pm 1.01$ \\
\hline F4 & $0.598 \pm 0.101$ & $0.668 \pm 0.101$ & $10.48 \pm 0.017$ & $1.11 \pm 0.001$ & $29.3 \pm 0.044$ \\
\hline F5 & $0.560 \pm 0.078$ & $0.693 \pm 0.067$ & $19.19 \pm 0.015$ & $1.24 \pm 0.006$ & $31.81 \pm 1.02$ \\
\hline F6 & $0.499 \pm 0.081$ & $0.595 \pm 0.063$ & $19.56 \pm 0.203$ & $1.19 \pm 0.003$ & $36.3 \pm 0.034$ \\
\hline F7 & $0.509 \pm 0.063$ & $0.630 \pm 0.058$ & $14.44 \pm 0.011$ & $1.23 \pm 0.004$ & $32.62 \pm 0.06$ \\
\hline F8 & $0.495 \pm 0.094$ & $0.595 \pm 0.088$ & $16.81 \pm 0.023$ & $1.20 \pm 0.003$ & $35.73 \pm 0.041$ \\
\hline F9 & $0.590 \pm 0.113$ & $0.693 \pm 0.091$ & $14.86 \pm 0.103$ & $1.17 \pm 0.008$ & $34.63 \pm 0.040$ \\
\hline F10 & $0.551 \pm 0.089$ & $0.675 \pm 0.076$ & $18.37 \pm 0.133$ & $1.23 \pm 0.003$ & $36.7 \pm 0.015$ \\
\hline
\end{tabular}

Note: ${ }^{*}$ Angle of repose $=$ Excellent: range $25-30 ;{ }^{*}$ Flow character $=$ Excellent: Compressibility index $=\leq 10$; ${ }^{*}$ Hausner ratio $=1.00-1.11$ 

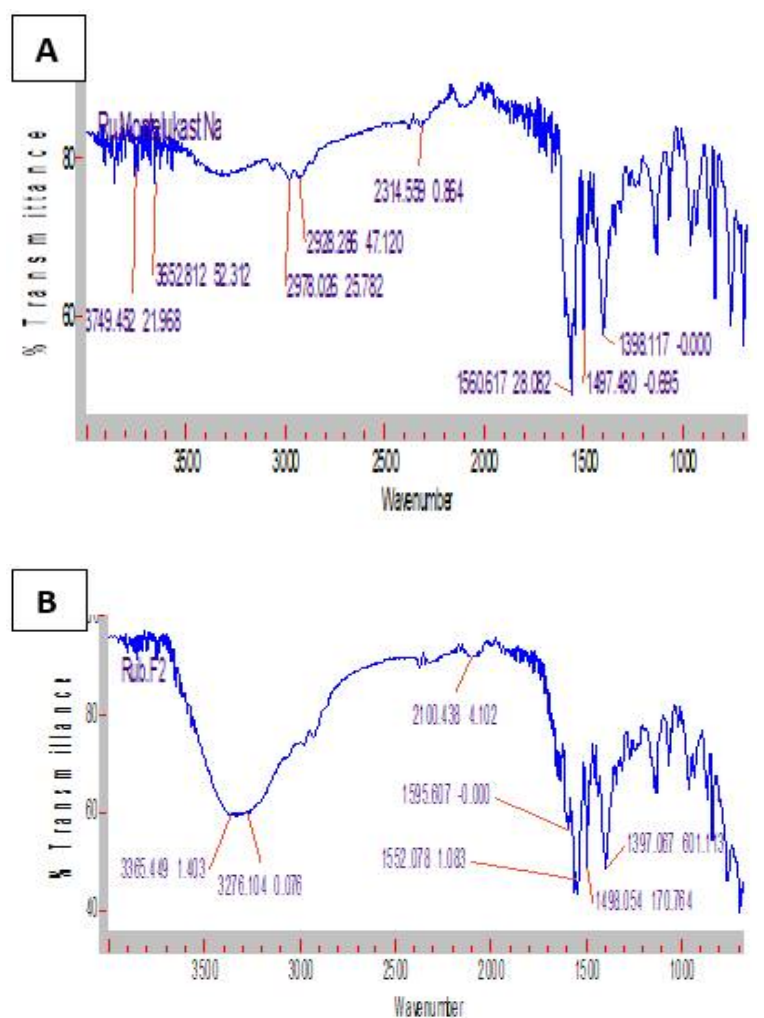

Figure 1: FTIR spectrum for (A) montelukast sodium and $(\mathrm{B})$ blended $\mathrm{F} 2$

In the current study the dissolution medium used was $0.2 \%$ of SLS instead of $0.5 \%$ as mentioned in USP and IP, selected on the basis of solubility data obtained from the experiments using 0.1 , $0.2,0.3$ and $0.5 \%$ of SLS in water. This solubility data was used for the development of a dissolution medium for montelukast sodium considering its poor solubility in water (Figure 2).

A CPB based on the better contrast of crospovidone and sodium bicarbonate was prepared with regard to two response factors. As per desirability of 1.0 the concentration of $X_{1} 20$ $\mathrm{mg}$ and $\mathrm{X}_{2} 16 \mathrm{mg}$ were obtained (Figure 3 ).

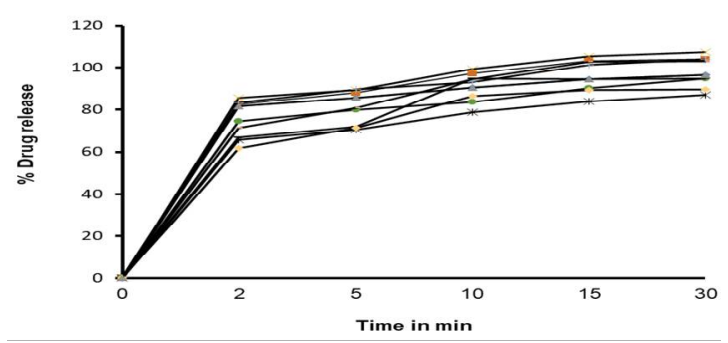

Figure 2: In vitro drug release profile of ODT (Mean \pm

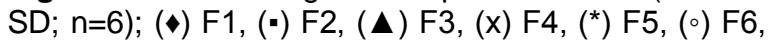

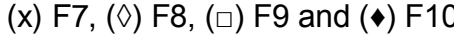

The appearance of the CPB was consistently round in shape and white in color. The average weight of the tablets was between 149.624 $151.00 \mathrm{mg}$ with standard deviation \pm 1.34 . The friability of CPB $\left(\mathrm{F}_{2}\right)$ was $0.27 \pm 0.085$ while the disintegration time ranged from $25.45-31.23$ seconds with SD \pm 1.672 thus validating the accuracy of software calculation of the portion of $\mathrm{X} 1$ and $\mathrm{X} 2$ components for predicting the friability and disintegration of tablets.

The dissolution data was subjected to different kinetic models as presented in Table 7 to check the order of drug release. Table 7 shows that the CPB failed to obey the zero order kinetics and the first-order and Weibull models described the drug release with $r^{2}$ value of 0.9926 and 0.9985 , respectively. The calculated Weibull $\beta$ parameter of $<1$ specified a parabolic curve with a steep slope. To calculate the differences between the formulations, Weibull has provided the best explanation.

The CPB was subjected to stability studies after blister packing of the tablets for six (6) months. No changes were observed in physical appearance of tablets at the end of study. However the wetting time changed from $30 \pm$ 0.11 to $37 \pm 0.20 \mathrm{~s}$ over the period. Small reduction in DT was also observed, i.e., $31.5 \pm 1.51$ to $25.5 \pm 2.30 \mathrm{~s}$ (Table 8 ).

Table 6: Pharmaceutical characteristics of formulated ODT (mean \pm SD)

\begin{tabular}{lccccc}
\hline Batch no. & $\begin{array}{c}\text { Hardness } \\
\text { NLT 4KP }\end{array}$ & $\begin{array}{c}\text { Friability } \\
\text { \% w/w }\end{array}$ & Wetting time (s) & $\begin{array}{c}\text { Disintegration } \\
\text { time (s) }\end{array}$ & $\begin{array}{c}\text { Drug content } \\
\text { (\%) }\end{array}$ \\
\hline F1 & $4.70 \pm 0.05$ & 0.73 & $20 \pm 0.11$ & $11.0 \pm 1.80$ & $90.69 \pm 1.20$ \\
F2 & $5.17 \pm 0.07$ & 0.37 & $25 \pm 0.18$ & $19.00 \pm 0.65$ & $103.02 \pm 0.81$ \\
F3 & $7.43 \pm 0.03$ & 0.46 & $39 \pm 0.10$ & $24.00 \pm 1.65$ & $97.49 \pm 1.78$ \\
F4 & $6.07 \pm 0.05$ & 0.32 & $30 \pm 0.21$ & $36.00 \pm 0.06$ & $101.58 \pm 0.88$ \\
F5 & $6.03 \pm 0.03$ & 0.38 & $33 \pm 0.19$ & $28.00 \pm 1.00$ & $95.13 \pm 0.80$ \\
F6 & $7.30 \pm 0.05$ & 0.38 & $37 \pm 0.25$ & $28.00 \pm 0.03$ & $90.35 \pm 1.78$ \\
F7 & $5.03 \pm 0.05$ & 0.29 & $45 \pm 0.12$ & $33.00 \pm 1.08$ & $99.90 \pm 0.40$ \\
F8 & $6.30 \pm 0.06$ & 0.42 & $40 \pm 0.15$ & $25.0 \pm 0.13$ & $96.20 \pm 1.19$ \\
F9 & $7.43 \pm 0.03$ & 0.62 & $29 \pm 0.22$ & $18.0 \pm 0.52$ & $100.41 \pm 0.48$ \\
F10 & $5.20 \pm 0.05$ & 0.24 & $39 \pm 0.13$ & $30.00 \pm 0.80$ & $99.80 \pm 0.46$ \\
\hline
\end{tabular}




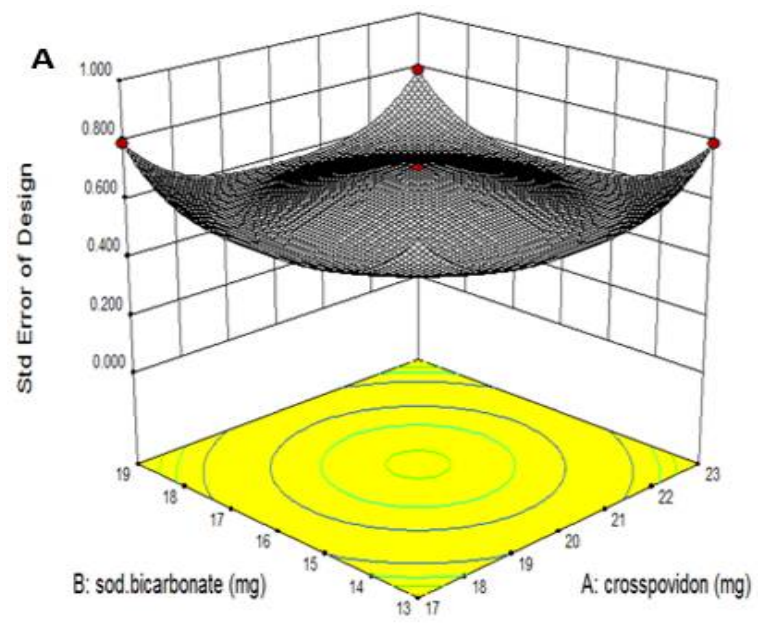

B

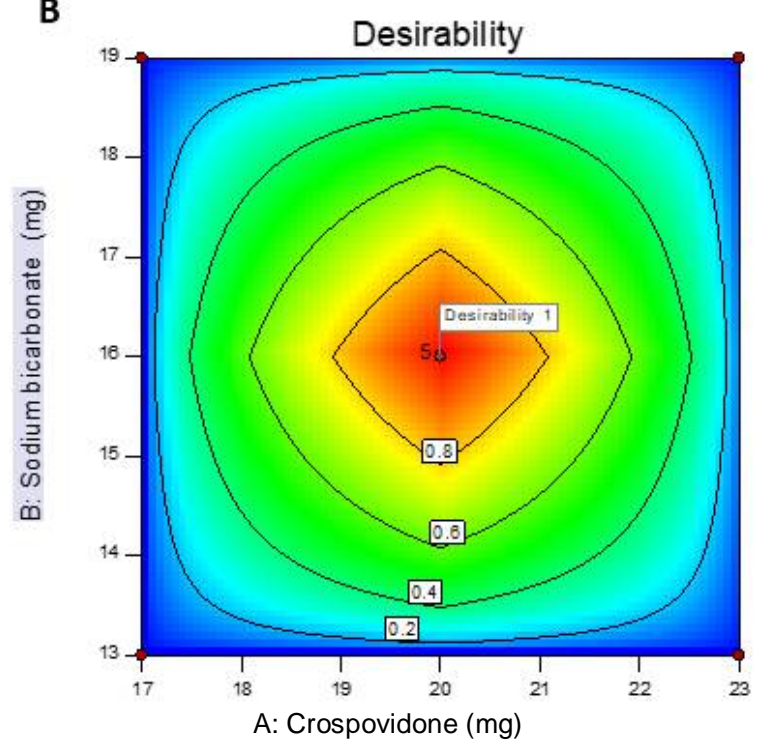

Figure 3: A) 3D surface plot of standard error of design of optimization batches; B) contour plot for desirability

\section{DISCUSSION}

After some trial batches, Ten ODT batches were prepared successfully by direct compression method. The optimization of formulation was done by using two factorial designs on Design Expert. The selection of excipient for montelukast sodium is a critical step in formulation development because it has tertiary hydroxyl groups, aromatic $\mathrm{C}-\mathrm{H}$ peaks and a carboxylic acid group which is present in the molecule in the form of a salt. Therefore it is necessary to maintain and hold the stability of compositions of montelukast especially when it contains sodium salt [24]. It is also reported that the stability of montelukast can be affected by the presence of microcrystalline cellulose because it contains peroxide that can catalyze the shifting of montelukast to its sulfoxide [24].

Therefore an effort has been made to prepare ODT of montelukast sodium with rapid disintegration time, designed to disintegrate directly in the patient's mouth without water within 60 seconds or less.

Two factorial designs were used to examine the effect of crospovidone and sodium bicarbonate on disintegration time and friability of tablets. Both of these substances have significant effect on DT and friability as well on the dissolution rate.

It was observed that increasing the concentration of crospovidone from lower to higher (10.5 to $16.2 \%$ ), resulted in decreased DT (Table 4). This occurred due to water absorbing nature of crospovidone (porous) by capillary and swelling mechanisms which developed internal pressure to increase disintegration [25]. In contrast, the hardness of tablets was reduced and friability was increased with increased crospovidone. It was gauged that the combination of crospovidone and sodium bicarbonate affects the release profile of drug. F3 containing lower

Table 7: Drug release kinetics data $\left(\mathrm{R}^{2}\right)$ for $\mathrm{CPB}$

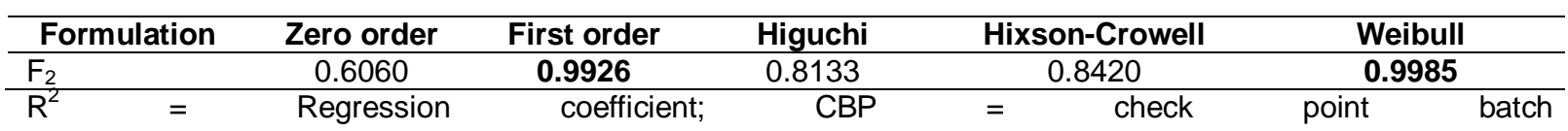

Table 8: Change in pharmaceutical parameters for CPB during stability studies

\begin{tabular}{|c|c|c|c|c|c|c|c|c|}
\hline $\begin{array}{l}\text { Time } \\
\text { (month) }\end{array}$ & $\begin{array}{c}\text { Physical } \\
\text { appearance }\end{array}$ & $\begin{array}{c}\text { Weight } \\
\text { variation }(\mathrm{mg})\end{array}$ & $\begin{array}{c}\text { Thickness } \\
\text { (mm) }\end{array}$ & $\begin{array}{l}\text { Hardness } \\
\text { (KP) }\end{array}$ & $\begin{array}{l}\text { Wetting } \\
\text { time (s) }\end{array}$ & $\begin{array}{c}\text { Friability } \\
(\% \mathrm{w} / \mathrm{w})\end{array}$ & $\begin{array}{c}\text { Disintegration } \\
\text { time (s) }\end{array}$ & $\begin{array}{c}\text { Drug } \\
\text { content (\%) }\end{array}$ \\
\hline & & & & & & & & \\
\hline & & & & & & & & .88 \\
\hline & No o & $5 \pm 1.04$ & & & & & & $99.59 \pm 1.95$ \\
\hline & No changes & $152.35 \pm 1.34$ & $3.85 \pm 0.73$ & $5.12 \pm 1.15$ & $37 \pm 0.20$ & 0.25 & $25.5 \pm 2.30$ & $100.78 \pm 0.86$ \\
\hline
\end{tabular}


concentration of crospovidone (10.6\%) and higher concentration of sodium bicarbonate (12.7 $\%$ resulted in $70.07 \%$ release of drug in 2 minutes. The percentage release of drug from F4 consisting of crospovidone (15.4\%) and sodium bicarbonate $(8.7 \%)$ was $85.71 \%$ in 2 minute.

It was demonstrated that the variation in the concentration of sodium bicarbonate doesn't affect the release of drug from its solid pharmaceutical composition as it works as buffer to decrease the $\mathrm{pH}$ by producing $\mathrm{CO}_{2}$. On the other hand, this experimental study showed the lowest disintegration time was for $\mathrm{F} 1$ with 24.24 $\mathrm{mg}(16.16 \%)$ of crospovidone and the \% release of drug was $81.7 \%$ in 2 min., but the hardness of tablets reached only up to $4.70 \pm 0.05$ [26]. It was also observed that MCC works as binder for direct compression of tablets to some extent. The studies show that MCC can optimize the dissolution and compactability of tablets if appropriately distributed in formulation [6].

The 3-D response surface plots of standard error and 2-D contour plot for desirability are the graphical representation of the regression analysis (Figure 3). These were used to define the association between the response and variable levels of each factor. The desirability plot was used to predict the optimized formulation as a combination of $\mathrm{X} 1$ and $\mathrm{X} 2$ acting as independent variables, against the best responses of disintegration time and \% friability (Figure 3). For further Variance analysis, ANOVA was performed for disintegration $\left(r^{2}=0.9988\right)$ and friability $\left(r^{2}=0.9961\right)$ of tablets at the $0.05<$ $p<0.10$ level where $\mathrm{F}=2.475$, indicating there is no significant difference in the tablets

Moreover, the composition of F2 selected for CPB showed optimized characteristics of DT, wetting time, friability, hardness with \% drug release of $r^{2}=0.9926$ (first-order kinetics) and $r^{2}$ $=0.9985$ (Weibull models).

Study of Literature shows that the stability of montelukast can be affected if MCC is present as a major diluents in the formulations [24]. The designated CPB (F2) formulation contained $68.54 \%$ of MCC. So accelerated stability study was performed to determine the degradation of montelukast sodium into the corresponding formulation. The results of the stability study, after 6 months of storage at $40 \pm 2{ }^{\circ} \mathrm{C}$ and $75 \pm 5$ $\% \mathrm{RH}$, showing that the proposed composition of ODT is appropriate for montelukast sodium tablets.

\section{CONCLUSION}

The ODT of montelukast sodium can be prepared by direct compression method. With the aid of Design Expert, the optimized batch can be obtained in a short period of time without involving any complicated steps. The resulting ODT possesses high mechanical strength with fast disintegration and dissolution characteristics leading to improved availability of the drug in vitro.

\section{DECLARATIONS}

\section{Acknowledgement}

The authors would like to thank Department of Pharmaceutics, RAK College of Pharmaceutical Sciences, RAK Medical and Health Sciences University for continuous support and encouragement.

\section{Conflict of interest}

No conflict of interest is associated with this work.

\section{Contribution of authors}

We declare that this work was done by the authors named in this article and all liabilities pertaining to claims relating to the content of this article will be borne by the authors. Shahnaz Usman conceived and designed the study, Rubina Rafiq analyzed and collected the data, Shahnaz Usman and Rubina Rafiq both wrote the manuscript while Kashif Ali Safdar helped in study design and handled design expert software. All authors read and approved the manuscript for publication.

All the authors read and approved the manuscript for publication.

\section{REFERENCES}

1. Lindgren S, Janzon L. Dysphagia. Prevalence of swallowing complaints and clinical findings. Med Clin North Am 1993; 77(4): 3-5.

2. Andersen O, Zweidorff OK, Hjelde T, Rodland EA. Problems when swallowing tablets. Tidsskr Nor Laegeforen 1995; 115(8): 947-949.

3. Chang RK, Guo $X$, Burnside BA, Couch RA. Fastdissolving tablets. Pharm Technol N Am 2000; 24(6): 52-58.

4. Roger RA1, Plazas FMJ, Galván CJ, Heras NJ, Ferragud AM, Gabarrón HE. Acceptance survey of a fast dissolving tablet pharmaceutical formulation in allergic 
patients. Satisfaction and expectancies. Allergol Immunopathol (Madr) 2006; 34(3): 107-112.

5. Gulf News, April 29, 2016 (accessed 8th February 2018)

6. Bouckaert S, Massart DL, Massart B, Rremon JP. Optimization of a granulation procedure for a hydrophilic matrix tablet design. Drug Dev Ind Pharm 1996; 22(4): 321-327.

7. Huang YB, Tsai YH, Yang WC, Chang JS, Wu PC. Optimization of sustained-release propranolol dosage form using factorial design and response surface methodology. Biol Pharm Bull 2004; 27(10): 1626-1629.

8. Rafiq ER, Usman S, Venkat R, Safdar AK. Formulation and In-Vitro Evaluation of Montelukast Oral Disintegrating (5 mg) Tablets: Effects of Diluents. Int $\mathrm{J}$ Pharm Sci Rev Res 2017; 43(2): 117-123

9. Rajeev S, Gali VS. Design and development of quick dissolving tablet containing loratadine by direct compression method. IJPCBS 2013; 3(3): 771-800.

10. USP 36-NF 31 (United States Pharmacopeia and National Formulary. Uniformity of Dosage Units, Weight Variation <905>, Rockville, MD: United States Pharmacopeia Convention; 2013; pp 431-434.

11. USP 36-NF 31 (United States Pharmacopeia and National Formulary. Tablet Friability $\langle 1216\rangle$, Rockville, MD: United States Pharmacopeia Convention; 2013; pp 974-975.

12. Park JH, Holman KM, Bish GA, Krieger DG, Ramlose $D S$, Herman CJ, Wu SH. An alternative to the USP disintegration test for orally disintegrating tablets. Pharm. Tech 2008; 32(8): 54-58.

13. Stoltenberg I, Breitkreutz J. Orally disintegrating minitablets (ODMTs) - A novel solid oral dosage form for paediatric use. Eur. J. Pharm. Biopharm 2011; 78(3): 462-469.

14. USP 36-NF 31 (United States Pharmacopeia and National Formulary). Disintegration $<701>$, Rockville, MD: United States Pharmacopeia Convention; 2013. $p$. 305-307.

15. Bolton S. Pharmaceutical Statistics. 2nd Ed. Marcel Decker Inc. New York; 1990; pp 234-236.

16. Gohel M, Patel M, Amin A, Agarwal A, Dave R, Bariya N. Formulation design and optimization of mouth dissolve tablets of nimesulide using vacuum drying technique. AAPS Pharm Sci Tech 2004; 5(3): 36-42.

17. ICH Q1A. Guidance for industry: Stability testing of new drug substances and products. (R2) 2003. Available from: https://www.fda.gov/downloads/drugs
18. Mali SS, Jadhav SB, Bharkad VB, Mohmmad J, Kadam VS, Kapse GR, Hadbe NB. An overview on fast disintegrating tablets. Pharma Science Monitor 2014; 5(2): 209-225.

19. Siddiqui MN, Garg G, Sharma PK. Fast dissolving tablets: preparation, characterization and evaluation: an overview. Int. J. Pharm. Sci. Rev. Res 2010; 4(2): 8796.

20. Pawar PB, Mansuk AG, Ramteke KH, Sharma YP, Patil SN. Mouth dissolving tablet: A review. Int. J Herb Drug Res 2011; 1(2): 22-29.

21. Ashish P, Harsoliya MS, Pathan JK, Shruti S. A reviewFormulation of mouth dissolving tablet. IJPCS 2011; 1(1): 1 - 8.

22. Rajeev S, Sagar GV. Design and development of quick dissolving tablet containing loratadine by direct compression method. IJPCBS 2013; 3(3): 771- 800.

23. USP 36-NF 31 (United States Pharmacopeia and National Formulary). Uniformity of Dosage Units, Weight Variation <905>, Rockville, MD: United States Pharmacopeia Convention; 2013. p. 431-434.

24. European Patent Specification. Date of publication: 21.04.2010 Bulletin 2010/16

25. Kornblum SS, Stoopak SB. A new tablet disintegrating agent: Cross-linked polyvinylpyrrolidone. J. Pharm. Sci 1973; 62(1): 43-49.

26. Flicker F, Betz G. Effect of crospovidone and hydroxypropyl cellulose on carbamazepine in high-dose tablet formulation. Drug Development and Industrial Pharmacy 2012; 38(6): 697-705

27. Li JZ, Rekhi GS, Augsburger LL, Shangraw RF. The role of intra- and extragranular microcrystalline cellulose in tablet dissolution. Pharm Dev Technol 1996; 1(4): 343355.

28. Gholve $S$, Shaikh $R$, Budhwant $S$, Bhusnure $O$. Development and validation of a simple UV spectrophometric method for the determination of montelukast sodium both in bulk and marketed dosage formulations. Int. Res. J. Pharm 2014; 5(4): 317-320.

29. Jyoti J, Savsani, Pratik P, Goti, Paru, Patel PB. Simultaneous UV spectrophotometric method for Estimation of Ebastine and Montelukast sodium in Tablet dosage form by Q-ratio method. Int. J Chem Tech Res. Coden (USA) 2013; 5(1): 47-55.

30. Bharate SS, Bharate SB, Bajaj AN. Interactions and incompatibilities of pharmaceutical excipients with active pharmaceutical ingredients: a comprehensive review. JEFC 2010; 1(3): 3-26. 